\title{
Editorial
}

\section{e Conventional Practice for Medical Conditions for Chronic Opioid Therapy}

Howard S. Smith, MD

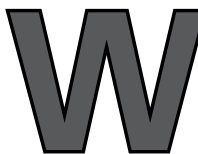

hen considering chronic opioid therapy (COT) for chronic noncancer pain, it has been proposed that it is prudent to contemplate 4 questions which may be useful and influence medical decision making (1):

1. What is the conventional practice?

2. Are there reasonable alternatives to COT?

3. What is the risk of adverse events?

4. Is the patient likely to be a responsible drug-taker?

Question 4 - (Is the patient likely to be a responsible drug-taker?) has received a lot of attention as well as a number of articles in the literature, including multiple tools designed to help clinicians "predict" whether an individual patient is likely to be a responsible drug-taker (2-6). Clinicians attempting to predict which patients may have a higher risk of exhibiting aberrant drug-related behavior on COT may be aided by: ORT (7), SOAPP-R (8), DIRE (9), DAST (10), SISAP (11), and clinical interview $(12,13)$, especially with significant self-reports of craving for opioid medications (14). As far as following a patient's adherence to the care plan, urine drug screening may be invaluable (15-19). Overall, opioids have been demonstrated to have some degree of efficacy for noncancer painful states (20-23). However, it seems that there is a relative scarcity of literature addressing the first question (e.g., what painful noncancer medical conditions are considered better suited for chronic opioid therapy and what painful noncancer medical conditions are considered less well-suited for chronic opioid therapy). This distinction may hold particular clinical significance, since definite methods exist that allow clinicians to predict which patients might be more likely to respond to opioids. Baseline pain intensity does not predict the outcome after an appropriate opioid titration (24). Kalso and colleagues (25) found no clear pattern of baseline pain (type or severity) or patient characteristics emerged that could be used to predict responders before the start of opioid treatment. However, a one month trial period appears sufficient to determine response and tolerability in most cases (25).

Eisenberg and colleagues' (26) study used both static and dynamic quantitative sensory testing (QST) on 40 healthy volunteers in order to test whether this methodology can predict the analgesic effects of oral oxycodone, as compared to a placebo, on latency to onset, pain intensity, and tolerance to the cold pressor test (CPT). The static QST results showed that heat pain thresholds predicted the magnitude of reduction in pain intensity in response to oxycodone treatment $[\mathrm{F}(1,22)=5.63, P=0.027, \mathrm{R}(2)=0.17](26)$. The dynamic QST results showed that temporal summation (TS) predicted the effect of oxycodone on the tolerance to $\mathrm{CPT}[\mathrm{F}(1,38)=9.11, P=0.005$, $R(2)=0.17(26)$. These results suggest that both static and dynamic QST have the potential to be useful in the prediction of the response to opioid treatment (26).

In an attempt to help primary care prescribers determine if their opioid prescribing habits were "usual"/average or a bit out of range of average (beyond 2 standard deviations of the mean opioid dose), --- Passik and Kirsh (27) published a schematic meant to help primary care physicians with

From: Albany Medical College, Albany, NY

Dr. Smith is Editor-in-Chief of Pain Physician, Professor \& Academic Director of Pain Management, Albany Medical College, Albany, New York. E-mail: smithh@mail.amc.edu

Disclaimer: There was no external funding in the preparation of this manuscript. Conflict of interest: None. 
opioid prescribing which they refer to asopioid prescribing "in and out of the box.". Again, like the first of the 4 questions discussed above, Passik and Kirsh (27) highlight "conventional practice" as one of their factors contributing to opioid prescribing "in or out of the box." Smith and colleagues (28) also noted that pain or painful conditions that are poorly responsive to opioids may predispose to opioid prescribing "out of the box." Smith also noted that there may be many factors which may contribute to variation in opioid responsiveness $(29,30)$, however, it does appear that certain pains or painful conditions may be better suited for opioid than others. Cancer and perioperative pain were "in the box" and pain syndromes in which opioid use is considered controversial was "out of the box."

The schematic in Fig. 1 was developed in an effort to shed light on which medical conditions may be considered more "conventional" to be treated with chronic opioid therapy and for which conditions that COT may be considered prescribing "out of the box." This schematic is based purely on one factor (medical condition) and is entirely biased. Obviously many other factors need to be taken into account when considering whether to initiate chronic opioid therapy for a particular patient.

A medical condition which tends to be less well suited for treatment with COT than other conditions is usually because of a higher risk for adverse effects with COT or perhaps due to a lower chance of achieving adequate analgesia. Every patient is different and there are many patients who have medical conditions that may be less well suited for COT, but who are doing very well on chronic opioid therapy, so that Fig. 1 is only meant to be a rough global guide in an attempt to aid primary care physicians who do not have significant experience in pain medicine. Figure 1 represents a rough overview of one factor (medical condition) that may be considered when clinicians are weighing the risks versus benefits of initiating COT in an individual patient. Additionally, because of the dearth of robust evidence, the "suitedness" of various medical conditions for COT is entirely biased and largely represents the beliefs and experience of the author.

These 4 questions may appear to somewhat "match up" with the "four A's", ---a mnemonic for following various domains of outcome of management with COT, developed by Passik and Weinreb (31).

Question 1 pertains to $\Rightarrow$ Analgesia

(Is there a high chance of achieving adequate analgesia with COT)
Question 2 pertains to $\Rightarrow$ Activities of daily living?

(Are there any nonopioid strategies which may lead to the patient's being more functional?

Question 3 pertains to $\Rightarrow$ Adverse Effects

(Factors which may increase the potential risk of patients experiencing adverse effects)

Question 4 pertains to $\Rightarrow$ Aberrant drug-taking behaviors

(Patients which may be at risk of exhibiting aberrant drug-taking behaviors may include: younger patients, patients who have contact with nonmedical users, patients with active psychiatric or substance abuse issues.)

Headache remains a painful condition where the medically indicated use of COT continues to be controversial. No consensus exists on headache-specific guidelines with respect to selecting patients for COT. However, it appears that a select and very limited group (estimate of $10-20 \%$ ) of refractory headache patients who meet criteria for COT respond with convincing headache reduction and functional improvement over the long-term (32). Medical conditions to the right of headache may be considered by some to be within the range of "conventional practice." Medical conditions to the left of headache in Fig. 1 may be considered less well-suited for COT than medical conditions to the right of headache.

Although there is no significant robust evidence that opioids are less well-suited for the pharmacologic treatment of fibromyalgia, in the anecdotal experience of the author typical opioids tend to suboptimal analgesia in a majority of fibromyalgia patients. Using positron emission tomography, Harris and colleagues (33) demonstrated that fibromyalgia patients have reduced mu opioid receptor binding potential within several brain regions associated with pain modulation, including: nucleus accumbens amygdala, dorsal cingulate, and striatum. These findings suggest that endogenous opioid analgesic activity in fibromyalgia patients may be normal or increased. Thus, intuitively administering exogenous opioids to fibromyalgia patients may not be all that fruitful in providing analgesia. Moreover, Younger and Mackey (34) conducted a pilot study and concluded that low-dose naltrexone hydrochloride may be an effective treatment for fibromyalgia, however, they attributed the beneficial effects of naltrexone to actions other than its "antagonistic" interaction with the mu opioid receptor. Similarly, low-dose naltrexone for irritable bowel syndrome (35).

Myofascial pain may respond to "local" therapy, 


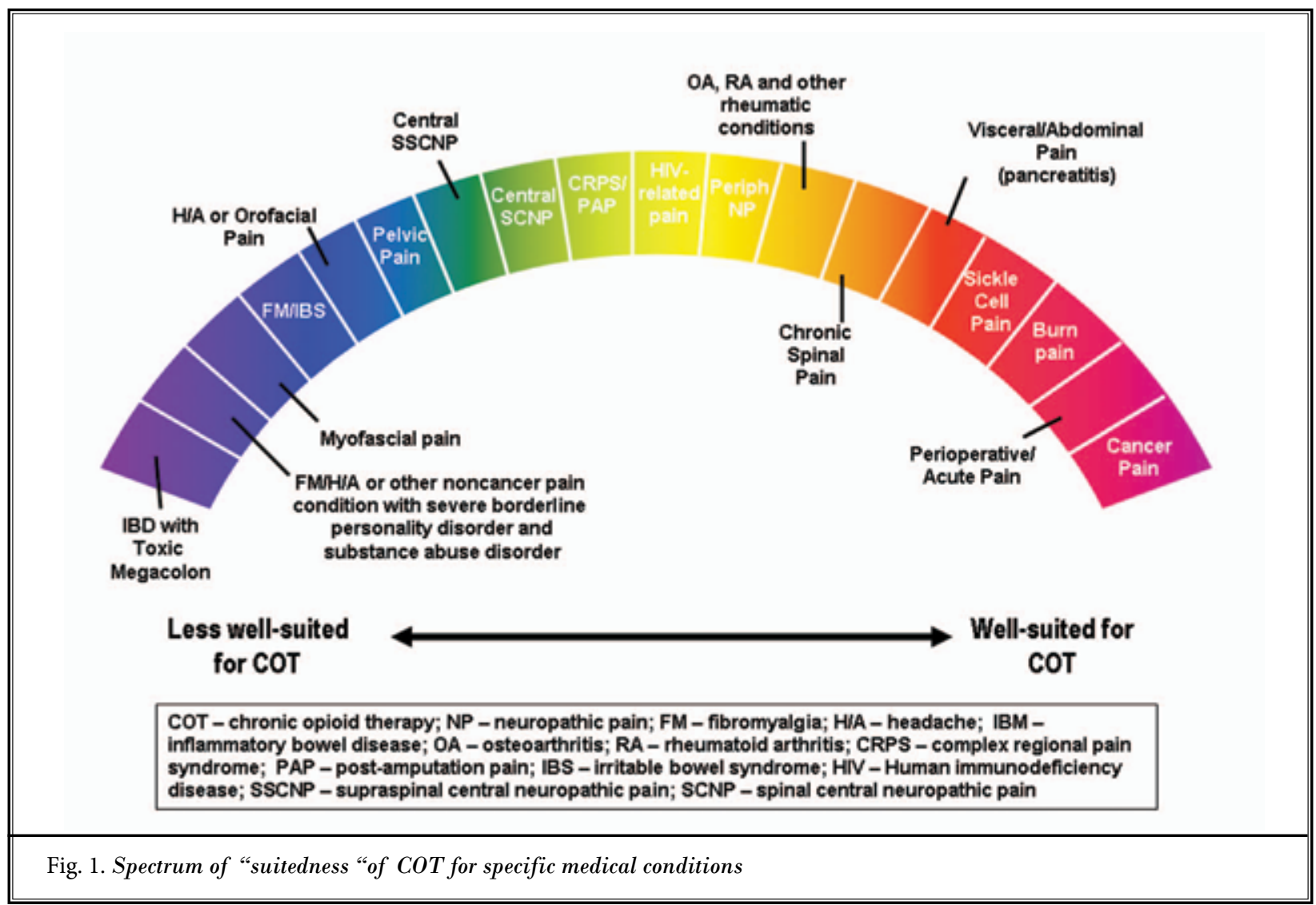

including: site-specific needle stimulation of peripheral points (acupuncture, dry needle therapy), injection of agents such as local anesthetics or botulinum toxin, electrotherapy, cryo/heat therapy, manual therapy/manual release techniques, biofeedback, exercise, massage, therapeutic ultrasound, and spray and stretch techniques $(36,37)$. There is a dearth of evidence for pharmacologic intervention in the management of myofascial pain; however, in spite of insufficient evidence, anecdotal experience may suggest that it is conceivable that agents such as muscle relaxants (e.g., cyclobenzaprine, baclofen, tizanidine or phenadrine) and antidepressant medications may provide some benefit to a small subset of patients with refractory myofascial pain (38-40). Opioids have not been shown to be effective for myofascial pain.

Opioids have been shown to be effective analgesic agents for patients with neuropathic pain $(41,42)$. However, neuropathic pain in general overall tends to be less responsive to opioids than nociceptive pain (43), although not all studies would support this $(41,3044$ is this supposed to be a reference number or numbers?
Furthermore, in contrast to Eisenberg et al (42), Smith and Meek (45) have published that central neuropathic pain may tend to be less opioid responsive than peripheral neuropathic pain. Also, within central pain states, Smith and Meek (45) proposed that supraspinal central neuropathic pain may be less opioid responsive than spinal central neuropathic pain (Fig. 2).

Despite that opioids are appropriately used to provide analgesia for refractory human immunodeficiency virus (HIV) painful syndromes, clinicians need to be cautious and consider the potential that opioids may affect or interact with antiretroviral therapy (46), affect HIV progression (47), or actually/facilitate or enhance nociceptive processes involved in contributing to pain in HIV-related pain states, and may provide suboptimal analgesia (48).

It has been suggested that patients with severe borderline personality disorder (BPD) symptoms (selfregulation deficits) are less suitable candidates for chronic opioid therapy; particularly those individuals with concomitant past histories of substance abuse and addiction $(49,50)$. A 7-year follow-up study by Links et 
al (51) indicates that in comparison with individuals with substance abuse alone, those with both substance abuse and BPD demonstrate higher levels of borderline personality psychopathology, self-destructive behavior, and suicidal ideation/behaviors.

White and colleagues (52) reviewed pain management in fulminating ulcerative colitis and stated that morphine is contraindicated in children with toxic megacolon (52), at least in part due to its detrimental effects on gastrointestinal transit.

Next clinicians may consider question 2: Are there reasonable alternatives to COT? There are many treatment strategies/approaches to ameliorate chronic pain, including: surgical, interventional (minimally-invasive/ procedural/injections), pharmacological nonopioidanalgesics and co-analagesics/adjuvants (e.g., acetaminophen, nonsteroidal anti-inflammatory drugscorticosteroids, antidepressants antiepileptic drugs, muscle relaxants, alpha-2-agonists, n-methyl-d-aspartate antagonists) (53), behavioral therapy/techniques, physical medicine approaches, complementary and alternative approaches (e.g., acupuncture), and neuromodulation approaches (e.g., transcutaneous electrical nerve stimulation [TENS], spinal cord stimulation).

The third question that clinicians may consider when deciding whether to initiate chronic opioid therapy is: What is the risk of adverse events? There are multiple factors which may predispose a patient to a higher risk of experiencing opioid adverse effects or to a specific opioid adverse effect $(54,55)$. Some of these factors include the same factors that may contribute to individual variations in opioid analgesic effectiveness (30). Individual pharmacogenomic differences in the metabolic machinery that patients possess (e.g., poor metabolizers) may affect the concentrations of opioid that ultimately reach the target receptors (29). Additionally, certain patients may inherently be more sensitive to a specific opioid's adverse effect (e.g., a patient with a history of motion sickness being at higher risk of opioid-induced nausea/vomiting).

Other factors that may predispose patients to a higher risk of experiencing opioid adverse effects include: drug-drug interactions, organ impairment, concomitant use of medications (e.g. anticholinergic agents [constipation]), benzodiazepine therapy (respiratory depression), certain comorbid medical conditions (e.g., severe cardiopulmonary compromise [decompensated heart failure], obstructive sleep apnea), rapid titration of inappropriately selected opioids, and lack of prophylactic measures to combat specific adverse effects (e.g., no senna therapy to prophylax constipation) (Fig. 3).

Despite the fact that many years ago morphine was considered one of the standard treatment options for acute decompensated congestive heart fail-

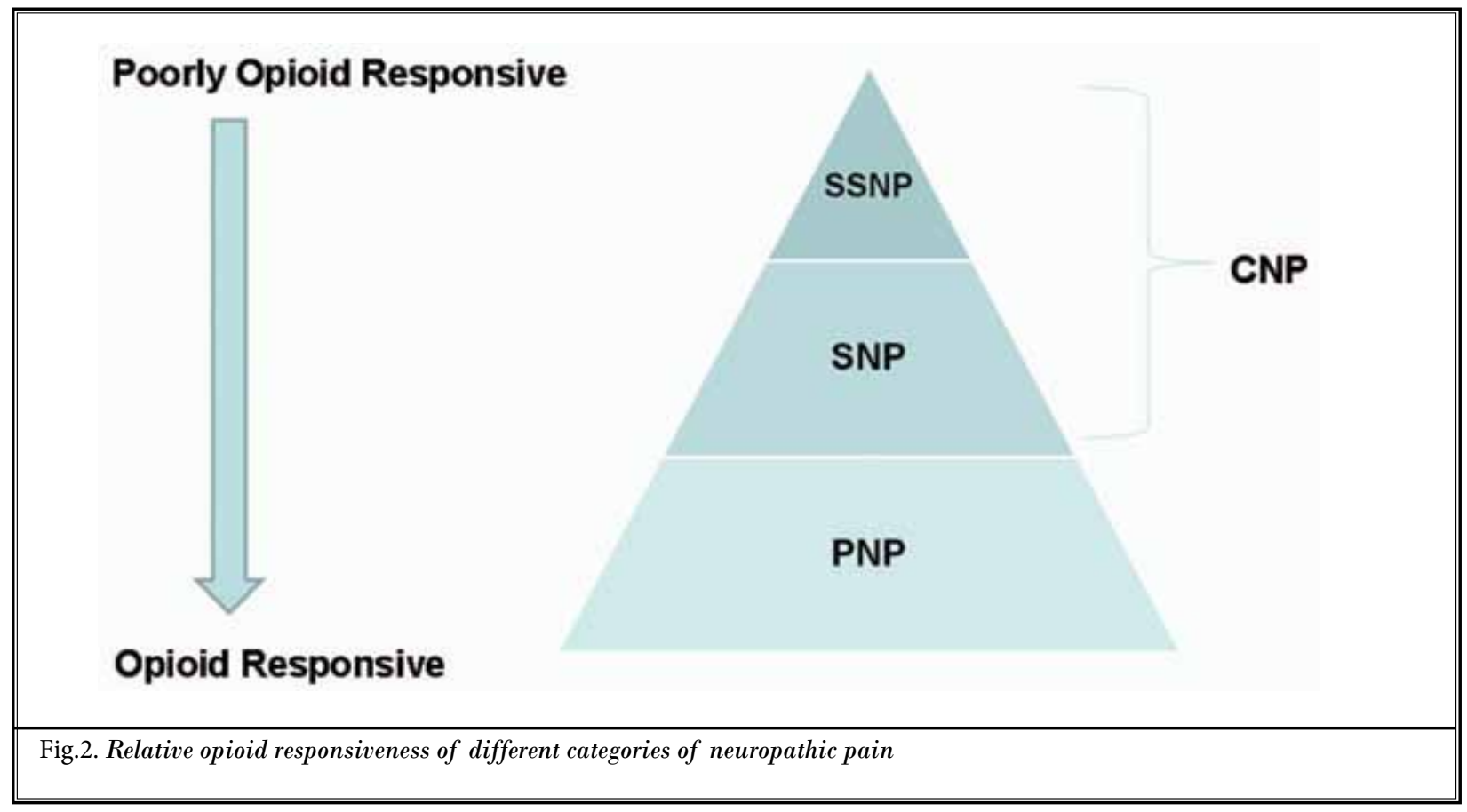




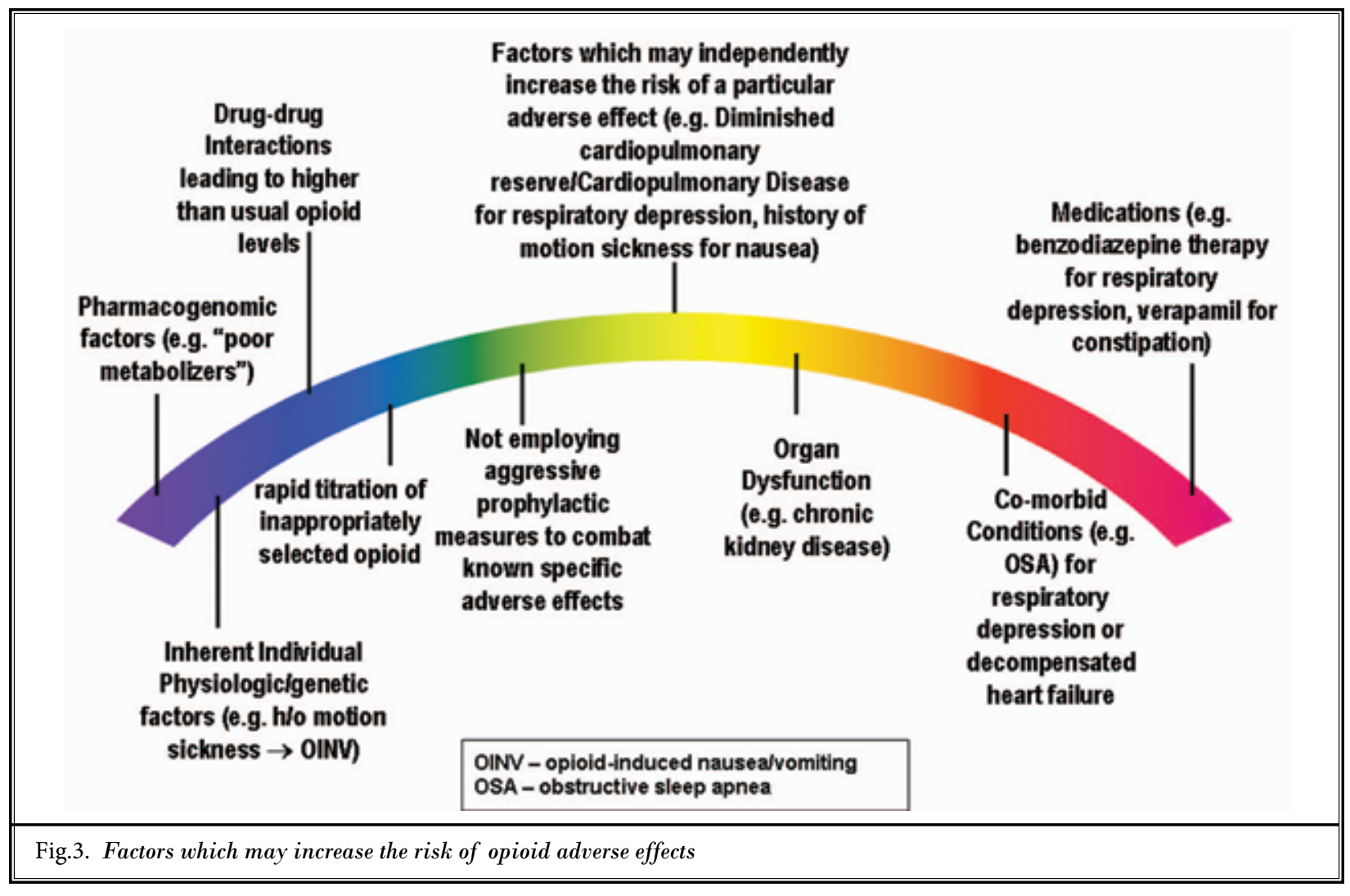

ure, Peacock et al (56) warned of the dangers of morphine therapy in acute decompensated heart failure. Their retrospective review of nearly 150,000 patients revealed an increased risk of mortality with an odds ratio of 5, despite extensive risk adjustment. They concluded that a prospective trial is needed. A retrospective study showing an association between morphine use and mortality is not proof of causation, but there is minimal evidence of any benefit from using morphine in heart failure (57). A review from 2004 found no evidence supporting the beneficial use of morphine in heart failure and 2 smaller retrospective studies suggest an association with harm (58).

Opioids may affect sleep-related breathing disorders (59-67), thus it appears that opioid analgesics are not particularly well suited for patients with obstructive sleep apnea, especially for patients on chronic benzodiazepine therapy (68).

Although some of the views presented above are extremely biased and unsubstantiated, it is hoped that clinicians can gain a greater appreciation of some of the many issues to consider when prescribing opioids.

\section{References}

1. Fine PG, Portenoy RK. A Clinical Guide to Opioid Analgesia. Vendrome Group, LLC, New York, NY, 2007.

2. Solanki DR, Koyyalagunta D, Shah RV, Silverman SM, Manchikanti L. Monitoring opioid adherence in chronic pain patients: Assessment of risk of substance misuse. Pain Physician 2011; 14:E199-E131.
3. Manchikanti L, Fellows B, Ailinani H, Pampati V. Therapeutic use, abuse, and nonmedical use of opioids: A ten-year perspective. Pain Physician 2010; 13:401435 .

4. Manchikanti L, Atluri S, Trescot A, Giodana J. Monitoring opioid adherence in chronic pain patients: Tools, techniques, and utility. Pain Physician 2008; 11:S155-
S180.

5. Manchikanti L, Singh A. Therapeutic opioids: A ten-year perspective on the complexities and complications of the escalating use, abuse, and nonmedical use of opioids. Pain Physician 2008; 11:S63-S88.

6. Manchikanti L, Cash KA, Damron KS, Mancgukonda R, Pampati V, McManus 
CD. Controlled Substance Abuse and IIlicit Drug Use in Chronic Pain Patients: An Evaluation of Multiple Variables. Pain Physician 2006; 9:215-225.

7. Webster LR, Webster RM. Predicting aberrant behaviors in opioid-treated patients: Preliminary validation of the Opioid Risk Tool. Pain Med 2005; 6:432-442.

8. Butler SF, Fernandez K, Benoit C, Budman $\mathrm{SH}$, Jamison RN. Validation of the revised Screener and Opioid Assessment for Patients with Pain (SOAPP-R).J Pain 2008; 9:360-372.

9. Belgrade $M J$, Schamber $C D$, Lindgren BR. The DIRE score: Predicting outcomes of opioid prescribing for chronic pain. J Pain 2006; 7:671-681.

10. Yudko E, Lozhkina O, Fouts A. A comprehensive review of the psychometric properties of the Drug Abuse Screening Test. J Subst Abuse Treat 2007; 32:189198.

11. Coambs RB, Jarry JL. The SISAP: A new screening instrument for indentifying potential opioid abusers in the management of chronic nonmalignant pain within general medical practice. Pain Res Manag 1996; 1:155-162.

12. Michna E, Ross EL, Hynes WL, Nedeljkovic SS, Soumekh S, Janfaza D, Palombi D, Jamison RN. Predicting aberrant drug behavior in patients treated for chronic pain: Importance of abuse history. J Pain Symptom Manage 2004; 28:250-258.

13. Moore TM, Jones T, Browder JH, Daffron S, Passik SD. A comparison of common screening methods for predicting aberrant drug-related behavior among patients receiving opioids for chronic pain management. Pain Med 2009; 10:1426-1433.

14. Wasan AD, Butler SF, Budman SH, Fernandez K, Weiss RD, Greenfield SF, Jamison RN. Does report of craving opioid medication predict aberrant drug behavior among chronic pain patients? Clin J Pain 2009; 25:193-198.

15. Manchikanti L, Malla Y, Wargo BW, Fellows B. Comparative evaluation of the accuracy of immunoassay with liquid chromatography tandem mass spectrometry (LC/MS/MS) of urine drug testing (UDT) opioids and illicit drugs in chronic pain patients. Pain Physician 2011; 14:175-187.

16. Christo P, Manchikanti L, Ruan X, Bottros $M$, Hansen $H$, Solanki DR, Jordan $\mathrm{AE}$, Colson J. Urine drug testing in chronic pain. Pain Physician 2011; 14:123-143.

17. Gilbert JW, Wheeler GR, Mick GE, Sorey BB, Herder SL, Richardson GB, Watts E, Gyartend-Dakwa K, Marino BS, Kenney CM, Siddiqi M, Broughton PG. Urine drug testing in the treatment of chronic noncancer pain in a Kentucky private neuroscience practice: The potential effect of Medicare benefit changes in Kentucky. Pain Physician 2010; 13:187-194.

18. Gilbert JW, Wheeler GR, Mick GE, Sorey BB, Herder SL, Richardson GB, Watts E, Gyartend-Dakwa K, Marino BS, Kenney CM, Siddiqi M, Broughton PG. Importance of urine drug testing in the treatment of chronic noncancer pain: Implications of recent Medicare policy changes in Kentucky. Pain Physician 2010; 13:167-186.

19. Manchikanti L, Manchukonda R, Pampati V, Damron KS, Brandon DE, Cash KA, McManus CD. Does random urine drug testing reduce illicit drug use in chronic pain patients receiving opioids? A prospective evaluation. Pain Physician 2006; 9:123-129.

20. Manchikanti L, Vallejo R, Manchikanti KN, Benyamin RM, Datta S, Christo PJ. Effectiveness of long-term opioid therapy for chronic non-cancer pain. Pain Physician 2011; 14:E133-E156.

21. Manchikanti L, Ailinani H, Koyyalgunta D, Datta S, Singh V, Eriator I, Sehgal N, Shah RV, Benyamin RH, Vallejo R, Fellows B, Christo PJ. A Systematic review of randomized trials of long-term opioid management for chronic non-cancer pain. Pain Physician 2011; 14:91-121.

22. Trescot AM, Glaser SE, Hansen H, Benyamin R, Patel S, Manchikanti L. Effectiveness of opioids in the treatment of chronic non-cancer pain. Pain Physician 2008; 11:S181-S200.

23. Trescot AM, Helm S, II, Hansen H, Benyamin R, Glaser SE, Adlaka R, Patel S, Manchikanti L. Opioids in the management of chronic non-cancer pain: An update of American Society of the International Pain Physicians (ASIPP) Guidelines. Pain Physician 2008; 11:5-62.

24. Mercadante S, Gebbia V, David F, Aielli F, Verna L, Porzio G, Ferrera P, Casuccio A, Ficorella C. Does pain intensity predict a poor opioid response in cancer patients? Eur J Cancer 2011; 47:713-717.

25. Kalso E, Simpson KH, Slappendel R, Dejonckheere J, Richarz U. Predicting longterm response to strong opioids in patients with low back pain: Findings from a randomized, controlled trial of transdermal fentanyl and morphine. BMC Med 2007; 5:39.

26. Eisenberg E, Midbari A, Haddad M, Pud D. Predicting the analgesic effect to oxycodone by 'static' and 'dynamic' quantitative sensory testing in healthy subjects. Pain 2010; 151:104-109.

27. Passik SD, Kirsh KL. The interface between pain and drug abuse and the evolution of strategies to optimize pain management while minimizing drug abuse. Exp Clin Psychopharmacol 2008; 16:400-404.

28. Smith HS, Kirsh KL, Passik SD. Chronic opioid therapy issues associated with opioid abuse potential. J Opioid Manag 2009; 5:287-300.

29. Smith HS. Opioid metabolism. Mayo Clin Proc 2009; 84:613-624.

30. Smith HS. Variations in opioid responsiveness. Pain Physician 2008; 11:237248.

31. Passik SD, Weinreb HJ. Managing chronic nonmalignant pain: Overcoming obstacles to the use of opioids. Adv Ther 2000; 17:70-83.

32. Saper JR, Lake AE 3rd, Bain PA, Stillman MJ, Rothrock JF, Mathew NT, Hamel RL, Moriarty M, Tietjen GE. A practice guide for continuous opioid therapy for refractory daily headache: Patient selection, physician requirements, and treatment monitoring. Headache 2010; 50:11751193.

33. Harris RE, Clauw DJ, Scott DJ, McLean SA, Gracely RH, Zubieta JK. Decreased central mu-opioid receptor availability in fibromyalgia. J Neurosci 2007; 27:10000-100006.

34. Younger J, Mackey S. Fibromyalgia symptoms are reduced by low-dose naItrexone: A pilot study. Pain Med 2009; 10: 663-672.

35. Kariv R, Tiomny E, Grenshpon R, Dekel R, Waisman G, RIngel Y, Halpern Z. Low-dose naltreoxone for the treatment of irritable bowel syndrome: a pilot study. Dig Dis Sci 2006; 51:2128-2133.

36. Lavelle ED, Lavelle W, Smith HS. Myofascial trigger points. Med Clin North Am 2007; 91:229-239.

37. Malanga GA, Cruz Colon EJ. Myofascial low back pain: A review. Phys Med Rehabil Clin N Am 2010; 21:711-724.

38. Leite FM, Atallah AN, El Dib R, Grossmann E, Januzze E, Andriolo RB, da Silva, EM. Cyclobenzaprine for the treatment of myofascial pain in adults. Co- 
chrane Database Syst Rev 2009 Jul 8;(3):CDoo6830.

39. Bendtsen L, Jensen R. Amitriptyline reduces myofascial tenderness in patients with chronic tension-type headache. Cephalalgia 2000; 20:603-610.

40. Manfredini D, Landi N, Tognini F, Orlando B, Bosco M. Muscle relaxants in the treatment of myofascial face pain. A literature review. Minerva Stomatol 2004; 53:305-313.

41. Kalso E, Edwards JE, Moore RA, McQuay $H$ J. Opioids in chronic non-cancer pain: Systematic review of efficacy and safety. Pain 2004; 112:372-380.

42. Eisenberg E, McNicol ED, Carr DB. Efficacy and safety of opioid agonists in the treatment of neuropathic pain of nonmalignant origin: Systematic review and meta-analysis of randomized controlled trials. JAMA 2005; 293:3043-3052.

43. Mercadante S, Gebbia V, David F, Aielli F, Verna L, Casuccio A, Porzio G, Mangione $S$, Ferrera $P$. Tools for identifying cancer pain of predominantly neuropathic origin and opioid responsiveness in cancer patients. J Pain 2009; 10:594600.

44. Moulin DE, Richarz U, Wallace M, Jacobs A, Thipphawong J. Efficacy of the sustained-relased hydromorphone in neuropathic pain management: Pooled analysis of three open-label studies. J Pain Palliat Care Pharmacother 2010; 24:200-212.

45. Smith HS, Meek PD. Pain responsiveness to opioids: Central versus peripheral neuropathic pain. J Opioid Manag 2011; In Press.

46. Batkis MF, Treisman GJ, Angelino AF. Integrated opioid use disorder and HIV treatment: Rationale, clinical guidelines for addiction treatment, and review of interactions of antiretroviral agents and opioid agonist therapies. AIDS Patient Care STDS 2010; 24:15-22.
47. Smith HS. Treatment consideration in painful HIV-related neuropathy. Pain Physician 2011; In Press.

48. Koeppe J, Armom C, Nielsen C, Johnson S. Ongoing pain despite aggressive opioid pain management among persons with HIV. Clin J Pain 2010; 26:190-198.

49. Sansone RA, Hawkins R. Fibromyalgia, borderline personality, and opioid prescription. Gen Hosp Psychiatry 2004; 26:415-416.

50. Sansone RA, Mueller M, Mercer A, Wiederman MW. Pain medication prescription and borderline personality disorder: A pilot study. J Opioid Manag 2010; 6:83-84.

51. Links PS, Heslegrave RJ, Mitton JE, van Reekum R, Patrick J. Borderline personality disorder and substance abuse: Consequences of comorbidity. Can J Psychiatry 1995; 40:9-14.

52. White M, Shah N, Lindley K, LloydThomas A, Thomas M. Pain management in fulminating ulcerative colitis. Paediatr Anaesth 2006; 16:1148-1152.

53. Kapural L, Kapural M, Bensitel T, Sesslwe DI. Opioid-sparing effect if intravenous outpatient ketamine infusions appears ahort-lived in chronic-pain patients with high opioid requirements. Pain Physician 2010; 13:389-394.

54. Vallejo R, Barkin RL, Wang VC. Pharmacology of opioid in the treatment of chronic pain syndromes. Pain Physician 2011; 14:E343-E360.

55. Benyamin R, Trescot AM, Datta S, Buenaventura R, Adlaka R, Sehgal N, Glaser SE, Vallejo R. Opioid complications and side effects. Pain Physician 2008; 11:S105-S120.56. Peacock WF, Hollander JE, Diercks DB, Lopatin M, Fonarow G, Emerman CL. Morphine and outcomes in acute decompensated heart failure: an ADHERE analysis. Emerg Med J 2008; 25:205-209.
57. Cattermole GN, Graham CA. Opiates should be avoided in acute decompensated heart failure. Emerg Med J 2009; 26:230-231.

58. Graham CA. Pharmacological therapy of acute cardiogenic pulmonary oedema in the emergency department. Emerg Med Aust 2004; 16:47-50.

59. Guilleminault C, Cao M, Yue HJ, Chawla P. Obstructive Sleep Apnea and Chronic Opioid Use. Lung 2010; 188:459-468.

6o. Yue HJ, Guilleminault C. Opioid medication and sleep-disordered breathing. Med Clin North Am 2010; 94:435-446.

61. Ramar K. Reversal of sleep-disordered breathing with opioid withdrawal. Pain Pract 2009; 9:394-398.

62. Alattar MA, Scharf SM. Opioid-associated central sleep apnea: A case series. Sleep Breath 2009; 13:201-206.

63. Mogri M, Desai H, Webster L, Grant BJ, Mador MJ. Hypoxemia in patients on chronic opiate therapy with and without sleep apnea. Sleep Breath 2009; 13:49-57.

64. Mogri M, Khan MI, Grant BJ, Mador MJ. Central sleep apnea induced by acute ingestion of opioids. Chest 2008; 133:1484-1488.

65. Webster LR, Choi Y, Desai H, Webster L, Grant BJ. Sleep-disordered breathing and chronic opioid therapy. Pain Med 2008; 9:425-432.

66. Teichtahl H, Wang D. Sleep-disordered breathing with chronic opioid use. Expert Opin Drug Saf 2007; 6:641-649.

67. Sharkey KM, Kurth ME, Anderson BJ, Corso RP, Millman RP, Stein MD. Obstructive sleep apnea is more common than central sleep apnea in methadone maintenance patients with subjective sleep complaints. Drug Alcohol Depend 2010; 108:77-83.

68. Webster LR. Considering the risks of benzodiazepines and opioids together. Pain Med 2010; 11:801-802. 
